\title{
23 \\ Complex versus Simple Stormwater Network Models - Modeling of the Keysers River Catchment
}

Gideon Joubert

In accordance with their objective of ensuring adequate stormwater drainage and the reduction of flood risk within the Cape Metropolitan Area, the Catchment, Stormwater and River Management Branch of the City of Cape Town commissioned a study to determine floodlines adjacent to the lower reaches of the Keysers River in the South Peninsula.

Information relating to the hydrological characteristics of the catchment, as well as the physical stormwater network, was collected and incorporated into a complex model of the catchment. When runoff from a recorded rainfall event was routed through the model, the simulation output was found to be significantly different from the observed catchment response.

A simplified model, which incorporated the overall physical characteristics and average hydrological parameters of the catchment, was run using the same rainfall event. In contrast to the results from the complex model, the output from the simple model showed a close match with the observed data. By reducing the time of concentration in the simple model, it was possible to produce a similar output to that of the complex model.

Joubert, G. 2004. "Complex versus Simple Stormwater Network Models - Modeling of the Keysers River Catchment." Journal of Water Management Modeling R220-23. doi:

10.14796/JWMM.R220-23.

(C) CHI 2004 www.chijournal.org ISSN: 2292-6062 (Formerly in Innovative Modeling of

Urban Water Systems. ISBN: 0-9683681-9-0) 
The various physical and hydrological parameters in the complex model were re-examined and it was found that the roughness coefficient used in the natural watercourse elements was the parameter with the most significant uncertainty. By increasing this parameter, the complex model response could be adjusted to reflect the observed catchment response.

We conclude from the modeling exercise that a complex system would not necessarily require complex modeling. Also, since the roughness coefficients used in natural channels and floodplains could significantly affect the response of a complex model, these need to be estimated as accurately as possible.

\subsection{Background}

One of the main objectives of the Catchment, Stormwater and River Management (CSRM) Branch of the City of Cape Town is to ensure effective stormwater drainage within the Cape Metropolitan area. In keeping with this aim, several hydrological studies were commissioned to investigate a number of rivers across the city and identify areas of potential flood risk. The brief for these studies therefore focussed on hydrological and hydraulic modeling for the purpose of determining floodlines in low-lying areas.

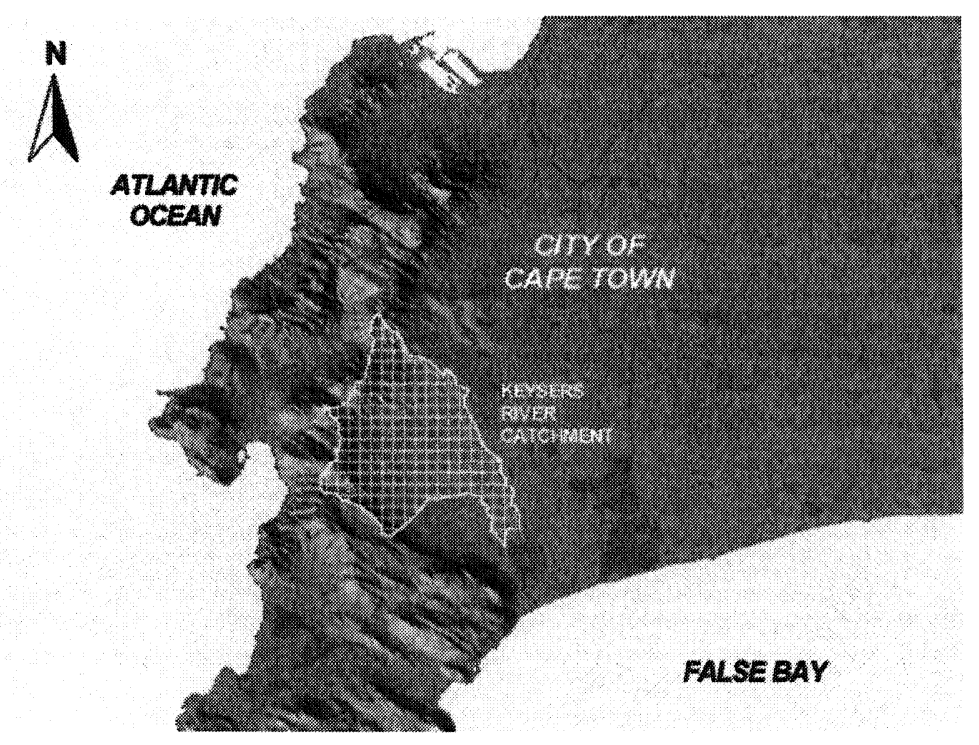

Figure 23.1 Keysers River catchment locality plan. 
One of the rivers investigated, the Keysers, is located in the Cape Town South Peninsula and drains a catchment area of $37 \mathrm{~km}^{2}$ (Figure 23.1). As demonstrated by Berg \& Reid (1999), the catchment includes varied land uses, such as urban, agricultural and natural areas, while the topography incorporates mountain, foothill and low-lying floodplain zones. The bulk of the stormwater drainage system comprises natural streams, but also includes a network of open channels, underground pipes and open water bodies. Although the catchment is relatively small, it is relatively complex hydrologically.

Although the modeling of the catchment by Joubert (2001 \& 2002) was carried out in phases over a period of several months, the exercise was essentially a single operation, since the basic assumptions were retained throughout and each subsequent phase extended the data and results of the preceding phase.

\subsection{Construction of the Catchment Model}

Data relating to topography, soils, vegetation, land use, detention storage and infrastructure was collected from numerous sources and collated for a detailed understanding of the catchment characteristics and stormwater network. Where required, unclear data was verified by means of field investigations and surveys.

A model of the physical network, consisting of junction, conduit, channel and storage elements, was set up using Visual SWMM and available as-built information. In order to reduce potential mathematical instability in the model, an attempt was made to keep the length of all link elements - i.e. pipes, culverts and channels - within a similar range. It was therefore necessary to insert intermediate nodes along many of the natural channel conduits, with the result that the final model consisted of more than 750 links or conduit elements.

Owing to its complexity, the catchment, was broken down into a number of hydrologically homogeneous units - i.e. zones of limited variation in slope, soil type, vegetation and land use. The demarcation was generally done along topographical lines, taking the influence of infrastructure into account and the catchment was eventually split into 111 sub-catchments. The SCS (U.S. Soil Conservation Service) method was selected for modeling stormwater runoff.

It must be noted that this level of complexity was dictated to a large extent by the ultimate goal of the modeling exercise, namely the determination of floodlines in the lower reaches of the catchment. 


\subsection{Calibration Data}

\subsubsection{Previous Studies}

There have been several attempts in the past to model the catchment, by Kirsten (1986) Obree (1994) and others. As could have been expected, the computed peak flows resulting from storm events of equivalent return period were significantly different from one model to the next. However, since no calibration was carried out, the results only provided the peak flow's order of magnitude.

\subsubsection{Existing Monitoring Devices \& Data}

According to Berg \& Reid (1999), the City of Cape Town operates four automatic rain gauges in the South Peninsula area either in, or in close proximity to, the Keysers River catchment.

In addition to the rain gauges, two monitoring devices are located at strategic points on the Keysers River. When functional, these devices record rainfall, channel velocity and flow depth. Unfortunately, owing to technical problems and/or vandalism, the available data sets are fragmented and inconsistent, with insufficient recorded rainfall, velocity and level data to provide any meaningful results for model calibration. It has therefore only been possible to calibrate against field observations during specific storm events.

\subsubsection{Rainfall Event of August 29, 2001}

On August 29, 2001, the Keysers River catchment experienced a storm event that lasted for approximately $15 \mathrm{~h}$. In the week prior to the event, there had been several smaller storms, with the result that the catchment was relatively moist. Localised flooding occurred in the residential suburb of Norfolk Park, when banks of the lower reaches of the Keysers River were overtopped and the underground stormwater system flooded.

Neither of the level/velocity monitoring devices was functional at the time, but from observations made and photos taken, a relatively detailed account of the extent of flooding at various times during the event was available. It was possible to establish water levels by checking the observed flooding against heights shown on detailed topographical maps of the area. The river channel in the affected area was modeled using accurate cross-section profiles and its performanceunder various flows was examined. From this exercise, approximate 
flows corresponding to the various levels could be estimated. The plotted hydrograph clearly showed the flood peak and the catchment response.

Of the four rain gauges in or near the catchment, only one was functional during the event. An examination of the available records for the four gauges indicated that there was a close correlation among them in terms of total rainfall depth and intensity distribution. Owing to the frontal nature of the rainfall typically experienced in Cape Town, this was not an unexpected result. It was assumed, for the study purposes, that the rainfall recorded at the single functional gauge was representative of the rainfall that did occur.

The 24-h depth of the storm recorded at the functional gauge was $59.8 \mathrm{~mm}$. According to Smithers and Schulze's (2000b) analysis of records from the South African Weather Bureau station 4723A Tokai (no longer in operation), the 24-h design rainfall depth for an event with an associated return period of $2 \mathrm{y}$ is $59 \mathrm{~mm}$ and this corresponds closely to the observed depth.

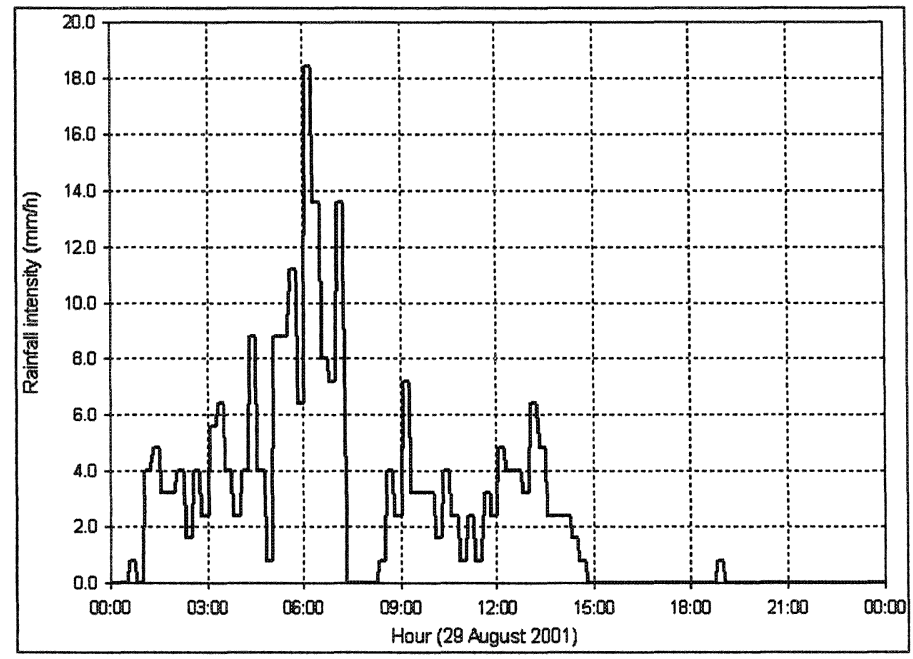

Figure 23.2 Rainfall event of 29 August 2001.

\subsection{Model Calibration Investigations}

\subsubsection{Initial Modeling Results}

The August $29^{\text {th }}$ rainfall event was routed through the model and the resulting hydrograph in the river channel adjacent to Norfolk Park plotted. The results from the initial runs showed an obvious disparity with the observed data. The 
computed hydrograph showed two distinct peaks, with the highest flow occurring approximately $6 \mathrm{~h}$ after the storm peak, while the field observations indicated a single flood peak occurring approximately $11 \mathrm{~h}$ after the storm peak. In addition, the computed peak flow was significantly higher than the peak flow estimated from the observed water levels. The differences were large enough to require explanation.

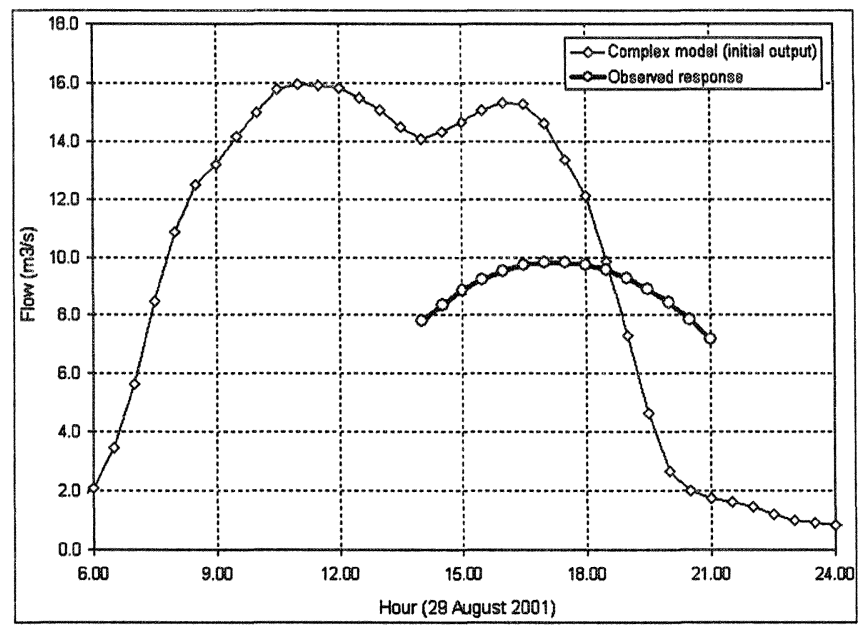

Figure 23.3 Initial modeling results compared with observed catchment response.

\subsubsection{Construction of a Simplified Model}

The model and calculations were re-checked, but no significant errors were found. Although it was certain that the real rainfall pattern across the catchment deviated somewhat from the event used in the modeling, it seemed unlikely that the difference could explain the discrepancies between the results.

It appeared that one or more of the modeling parameters would have to be adjusted, but, owing to the complexity of the model, the run time required to simulate the event on a desktop computer was of the order of 50 minutes, so that checking minor changes to the model would be a time-consuming exercise.

To gain a better understanding of the problem, a simplified single catchment model was constructed in Visual SWMM, consisting of an upstream 'input' node linked to an 'outlet' node. The overall physical characteristics and average hydrological parameters of the total catchment were used to define the 
'input' node, while the 'outlet' node was defined using the same conditions as at the outlet of the complex model. The conduit linking the two nodes was equivalent to the section of natural channel in the vicinity of Norfolk Park.

Since the run time of the simplified model was short enough to allow numerous parameters to be varied and the effect to be determined in a matter of seconds, rather than hours, it was possible to test many combinations in a relatively short time. The simplified model would therefore be a tool to identify the relative sensitivity of the various parameters.

\subsubsection{Simplified Model Results}

The same storm event (August 29) was routed through the simplified model and the resulting hydrograph, in contrast to that produced by the complex model, showed a better fit to the observed data -i.e. a single flood peak at approximately $12 \mathrm{~h}$ after the storm peak.

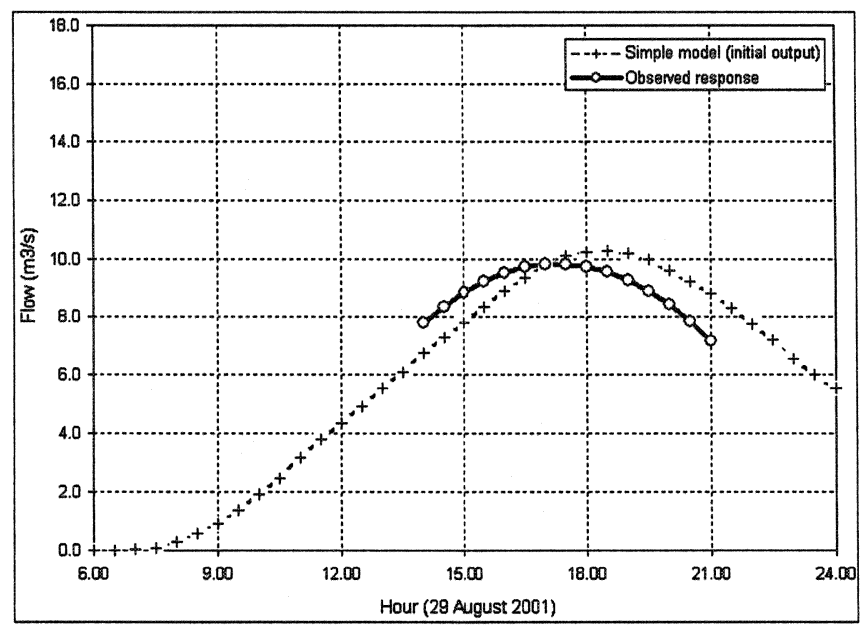

Figure 23.4 Initial results from the simplified model.

Although it appeared that the simplified model gave a better result, this may have been purely coincidental, so several of the model parameters were varied in order to check whether the simplified model could be altered to produce a similar output to the complex model. The investigation confirmed the following:

- reducing the initial abstraction factor increased the peak flow, but had little effect on the response time of the catchment; 
- increasing the SCS curve number $(\mathrm{CN})$ increased the peak flow and reduced the response time to a certain extent, but the reduction in the response time was limited; and

- reducing the catchment hydraulic length or conversely, increasing the hydraulic width, had a significant effect on both the peak flow and the response time.

Ultimately, it was found that if the hydraulic length of the model catchment was reduced by more than $50 \%$, the simplified model could be made to produce a similar output to the complex model -i.e. two distinct peaks in the hydrograph, with the first occurring approximately $6 \mathrm{~h}$ after the storm peak.

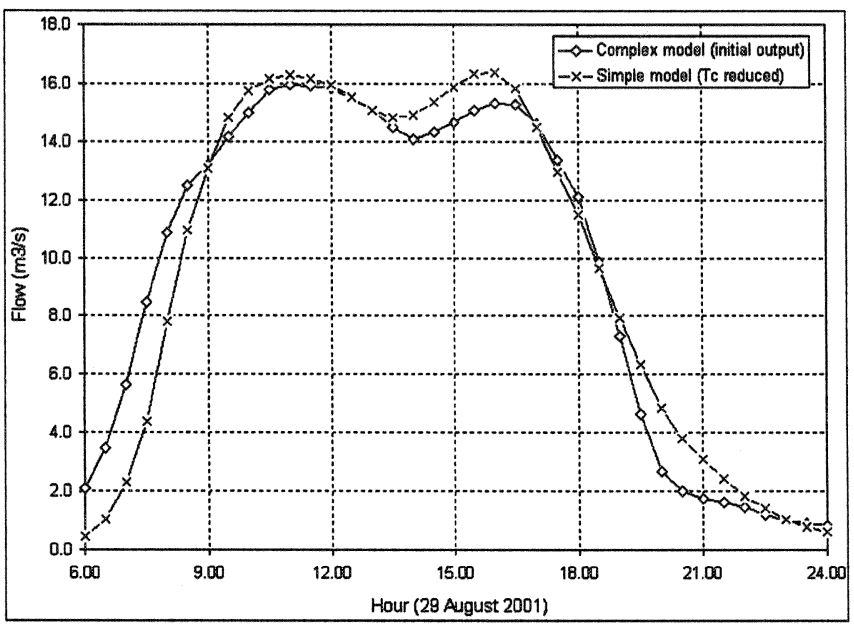

Figure 23.5 Revised simplified model results compared with the complex model initial output.

In terms of the hydrology, the main effect of reducing the hydraulic length of the catchment in the simplified model was to reduce the time of concentration (Tc) and thereby reduce the response time of the catchment. However, since the complex model could essentially be regarded as a hydraulic model of the physical stormwater network, with the various sub-catchments draining into the network at specific locations, reducing the hydraulic length of the individual sub-catchments would not be justified. Furthermore, since the individual contribution of each sub-catchment to the overall system was relatively small, the response time of the catchment as a whole had to be dependent on some physical characteristic that applied to the catchment as a whole. 


\subsubsection{Roughness Coefficients}

Most of the physical parameters used to define each of the hydraulic elements in the model, could be easily measured or calculated. In contrast, the hydraulic roughness of natural channels and floodplains could not be directly measured, owing to the highly variable nature of these elements.

There are numerous guidelines for estimating the Manning roughness coefficient (n) and, although those offered in the literature are reasonably consistent for items such as manufactured pipes and constructed channels, there is considerable variation for natural streams and channels. For example, according to Rooseboom et al. (1993), the $n$ value for natural straight streams can range between 0.031 and 0.050 , depending on the hydraulic radius of the channel. In comparison, the $n$ value suggested by Chow (1973) for a similar channel varies from 0.025 to 0.040 .

Under normal circumstances, maintenance crews employed by the City of Cape Town clear the metropolitan natural watercourses of excess vegetation annually in February and March - i.e. towards the end of summer. By the end of August, there is significant growth in the channels and on the stream banks which obviously affects the hydraulic functioning of these watercourses.

The $n$ values that had originally been selected for the hydraulic elements such as pipes, culverts and lined channels were therefore assumed to be reasonable, but the Manning coefficients for the natural channels were reexamined. It was found that although the $n$ values fell within acceptable ranges, they tended to correspond more with well-maintained channels, than with overgrown channels.

The roughness coefficient of any hydraulic element has a direct influence on the flow velocity and by extension, the overall catchment response time when such elements are aggregated. So the problem with the complex model might simply be that the roughness coefficients used in the natural channels were too low. To test this, the $\mathrm{n}$ values for these watercourse elements in the complex model were increased systematically and the simulation results from each run compared to the observed catchment response.

It was found that by increasing the $n$ values by $60 \%$, the complex model output matched the observed response fairly closely. In contrast to the initial values, the revised roughness coefficients, congregated towards the unmaintained or overgrown end of the ranges suggested in the literature. Several examples are given in Table 23.1 . 
Table 23.1 Comparison of Manning roughness coefficient in natural channels.

\begin{tabular}{lcc}
\hline Description of Natural Channel & Original n & Revised n \\
\hline $\begin{array}{l}\text { Natural channel gently curving, light vegetation in } \\
\text { channel \& on banks }\end{array}$ & 0.030 & 0.048 \\
$\begin{array}{l}\text { Natural straight channel, reeds on bank, encroaching } \\
\text { on main channel }\end{array}$ & 0.035 & 0.056 \\
$\begin{array}{l}\text { Foothill stream, few cobbles or boulders, densely } \\
\text { vegetated banks }\end{array}$ & 0.045 & 0.072 \\
Floodplain, vegetated with reeds, shrubs and trees & 0.075 & 0.120 \\
\hline
\end{tabular}

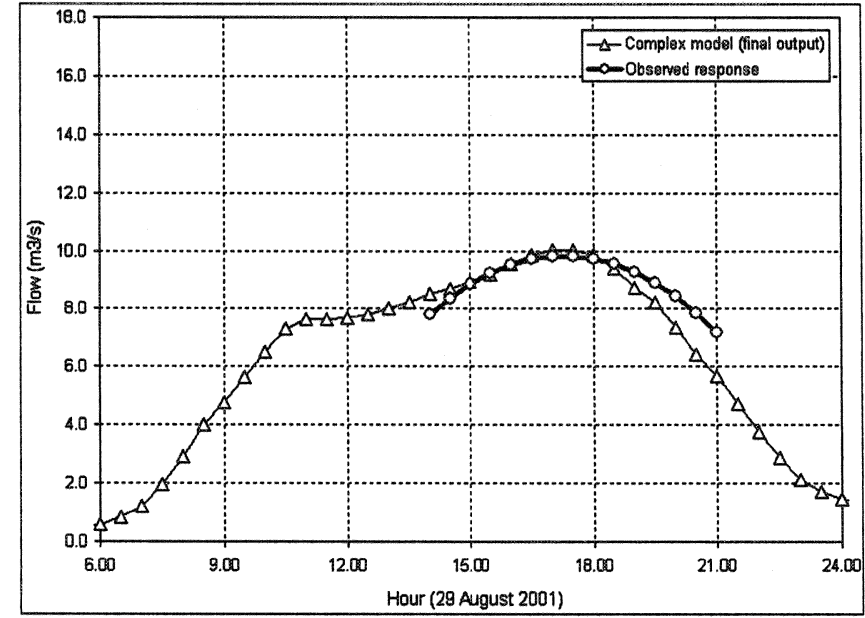

Figure 23.6 Revised complex model output compared with observed catchment response.

\subsubsection{Analysis of Model Results}

The revised complex model cannot be considered calibrated since only a single event was used in the exercise. Furthermore, since the comparison of results was carried out at a single point on the drainage network, the results are only applicable at that point. However, owing to the lack of additional calibration data, there was little more that could be done. 


\subsection{Conclusions}

Several conclusions can be drawn from the above case. Many of these were self evident, but have been included below for the sake of completeness.

- Hydrological and hydraulic modeling of a catchment is unlikely to produce meaningful results without adequate calibration.

- A complex system will not necessarily require complex modeling. The level of complexity should be appropriate to the purpose of the modeling exercise.

- The availability of reliable calibration information is essential to producing modeling results that can be used with any degree of confidence.

- Roughness coefficients used in natural channels and floodplains can significantly affect the response of a complex model and therefore need to be estimated as accurately as possible.

- In a natural watercourse, it is not reasonable to assume that the roughness coefficient of the channel will remain constant throughout the year, because of factors such as maintenance and vegetation growth.

\section{References}

Berg, R.R and Reid, S. 1999. Sand River Catchment Management Plan Formulation - Phase 1. Ninham Shand Consulting Engineers Report 2975/8722. Report to City of Cape Town. pp 16 - 28; Appendix B

Chow, V.T. 1973. Open-Channel Hydraulics International Student Edition. McGrawHill.ISBN0-07-Y85906-X.pp 110-113

Joubert, G. 2001. Keysers River Hydrological Study - Phase 2. Jeffares \& Green Consulting Engineers Report No. 05-1036. Report to City of Cape Town. pp10 - 36; Appendices B, H \& I.

Joubert, G. 2002. Sand River Catchment Hydrological Study - Phase 3: Keysers River Flood Line Determination. Jeffares \& Green Consulting Engineers Report No. 051213. Report to City of Cape Town. pp 6 - 10; Appendices C \& E.

Kirsten, N. 1986. Keysers River Flood Control Scheme. City of Cape Town City Engineer's Department Stormwater Management Report No 3. pp 3 - 6; Annexures 6A \& 6B.

Obree, M.R. 1994. Keysers River Preliminary Catchment Study. City of Cape Town City Engineer's Department Stormwater Management Report. pp 2 - 4.

Rooseboom, A; Basson, M.S; Loots, C.H; Wigget, J.H. and Bosman, J. 1993. Road 
Drainage Manual. Department of Transport, Pretoria, RSA. ISBN 0-908381-395. pp 3-22.

Smithers, J.C. and Schulze, R.E., 2000b. Long duration design rainfall estimates for South Africa. WRC Report No. 811/1/00. Report to Water Research Commission, Pretoria, RSA. pp 4. 